\title{
A qualitative assessment of nutrition knowledge levels and dietary intake of schoolchildren in Hyderabad
}

\author{
T Vijayapushpam* , Krishna Kumari Menon, D Raghunatha Rao and Grace Maria Antony \\ National Institute of Nutrition (Indian Council of Medical Research), Jamai Osmania PO, Hyderabad - 500007 , \\ India
}

Submitted 21 October 2002: Accepted 3 April 2003

\begin{abstract}
Objectives: To assess the nutrition knowledge levels and dietary intake pattern of schoolchildren belonging to two groups of different socio-economic status (SES; high income/high SES and low income/low SES).

Design: A purposive sampling method was employed. A validated food-frequency questionnaire was administered to assess the dietary intake of schoolchildren in four schools from two different socio-economic strata in the month of January 2001. The children were divided into two groups, one serving as the experimental group and the other as the control group.

Subjects: Two hundred and seventy-two children aged between 12 and 14 years.

Results: There was a significant improvement $(P<0.001)$ in the knowledge levels of high-SES schoolchildren as compared with low-SES schoolchildren. A significant difference was observed in the intake of protective foods like milk and milk products, green leafy vegetables and fruits between the two income groups. However, children from the high SES background preferred fast foods such as noodles and corn flakes to traditional foods. Irrespective of income group, most of the children consumed carbonated beverages.

Conclusions: There was a significant difference in the intakes of protective foods and fast foods between the different income groups. However, the increased intake of fast foods and carbonated beverages by the children irrespective of SES needs to be discouraged as a part of nutrition education. The study indicated the need for repeated interventions for improvement of nutrition knowledge levels in low-SES children.
\end{abstract}

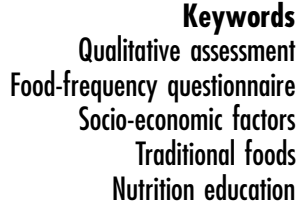

It is important to study the existing pattern of dietary intake in a given population to determine the food preferences, beliefs and food fads of the community, so as to plan an appropriate nutrition education package. Estimation of the community's dietary intake and precision in the collection of data depend on the resources available and the characteristics of the study population. Data on national food availability and food consumption patterns of communities provide information on dietary intake for large populations. Diet records, dietary recall methods and food-frequency questionnaires (FFQs) are common tools employed to measure the food consumption patterns of individual subjects in the epidemiology of diet-related diseases $^{1}$. The food frequency method involves the collection of information about a list of food items for which average frequency of consumption is determined with reference to a specified period in the past. It requires neither specialised training for respondents nor a lengthy interview, and hence places a lighter burden on respondents, which encourages their participation.
Compared with diet history and 24-hour recall methods, the FFQ method requires less specialised interviewer training. It can be undertaken by face-to-face personal interview, by telephone or by self-administration including mail surveys ${ }^{2,3}$.

In any dietary survey, the respondent is usually the mother or the housewife who is involved in the preparation of food for the family. The present study was part of a research project on 'Content analysis of nutrition- and health-related curriculum in secondary schools and development of a nutrition education strategy for schoolchildren'. Since it was concerned with schoolchildren, an attempt was made to elicit information from them with regard to their food preferences and practices.

Thus, in the present investigation, a nutrition knowledge assessment questionnaire and an FFQ were administered to the schoolchildren of different socioeconomic status (SES) to assess their nutrition knowledge levels and usual dietary intake. 


\section{Methods}

For this study about 20 schools in the twin cities of Hyderabad and Secunderabad, India, were contacted; four schools (two government-run and two under private management) were selected at random and gave consent to participate. The purposive sampling method was employed to select 8th class students as study subjects in the four schools. Among the schools selected, two schools were from low and lower-middle income groups (hereafter referred to as low income/low SES) and the other two were from upper-middle and high income groups (referred to as high income/high SES). The children were further divided into two groups, one was considered as the experimental group while the other served as the control group. Nutrition education was given only to the experimental group. According to the World Health Organization (WHO), children in the age group of 10 to 18 years are considered as adolescents. Therefore, in the present study, all students between 12 and 14 years of age from the 8th class in each school were selected.

\section{Knowledge assessment}

A knowledge assessment questionnaire was administered to the schoolchildren to find out their level of nutrition knowledge. A score was given for each question. All correct answers were given a score of 2 and wrong answers were given 0 score. The scores of all of the questions were summed up to give the total score of each child.

This information served as baseline data for the study. Based on these data lacunae in the nutrition knowledge levels of the schoolchildren were assessed, and different folders on various themes such as protein, fat, vitamin A, vitamin C, vitamin B complex, iron and iodine were developed. In addition, one set of colour slides was also developed. Intervention was carried out in the experimental group of both schools using slides, folders and posters. With an interval of two days from the time of intervention, the same knowledge assessment questionnaire that was used to collect baseline data was again administered to the schoolchildren to assess the postintervention nutrition knowledge levels.

\section{Assessment of dietary intake}

This study was carried out between January and March 2001. The standardised and validated FFQ developed by the National Institute of Nutrition, which has been used in different surveys, was employed to collect the dietary intake of the schoolchildren ${ }^{4}$. Details on the frequency of intake of 68 food items such as cereals, pulses, green leafy vegetables, other vegetables, fruits, milk and milk products were collected. Since the respondents came from an urban area, data on processed foods, fast foods and carbonated drinks were also collected. Frequency of intake was recorded as (1) daily; (2) three or four times a week; (3) once or twice a week; (4) once a month or occasionally. Socio-economic characteristics of the families, food preferences, health- and nutrition-related knowledge of the children were also assessed. Chi-square tests were applied to analyse the variation in frequency of intake of different foods between children of low and high SES. Analysis of the data was carried out using SPSS version 10.0 (SPSS Inc., Chicago, IL, USA).

\section{Results}

The sample comprised 272 children (108 boys, 164 girls). Among the study children, $52 \%$ were from the low socioeconomic group and the rest were from the higher socioeconomic group. The average monthly family income in the low-SES group was Rs 4268 (standard deviation (SD) 2177) while that in the high-SES group was Rs 18454 (SD 8225).

\section{Assessment offood intake}

The results of the food frequency survey indicated that, irrespective of SES, all children consumed rice daily. Eighty per cent of children belonging to the high-SES group consumed wheat daily compared with $44 \%$ in the low-SES group. Nine per cent of the low-SES group consumed the millet jowar (Sorghum vulgare) compared with $2 \%$ in the high-SES group. The intake of millet was considerably low in both groups. Pulses were consumed more frequently by children in the high-SES group than by children in the low-SES group $(P<0.001$, Table 1$)$.

However, no difference was observed in the consumption of roots and tubers between high- and low-SES groups, as $90 \%$ of the children in both groups consumed roots and tubers daily; mostly onions (Allium cepa) and potatoes (Solanum tuberosum).

In the case of intakes of non-vegetarian foods like poultry and eggs, the daily intake pattern remained the same in both groups. However, a greater number of children consumed non-vegetarian foods at least once or twice a week in the low-income group (Table 1). Among children belonging to the high-SES group, 92\% consumed at least one vegetable daily and $44 \%$ consumed nuts and oil seeds daily, whereas among children of the low-SES group only $14 \%$ consumed vegetables, nuts and oil seeds daily. A significant difference was observed in the frequency of intake of nuts and oil seeds between highand low-SES groups $(P<0.001)$.

\section{Protective foods}

Frequencies of consumption of major protective foods green leafy vegetables (GLV), milk and milk products and fruits - are given in Fig. 1. Children from the high-SES group consumed GLV more frequently, with $96 \%$ of them consuming GLV daily (Fig. 1). Daily intake of fruits was significantly higher (79\%) among children with high SES as compared with children with low SES (32\%). With regard 
Table 1 Frequency of intake (\%) of different foods among schoolchildren attending selected schools in Hyderabad, by socio-economic status (SES)

\begin{tabular}{|c|c|c|c|c|c|c|c|c|}
\hline \multirow[b]{2}{*}{ Food item } & \multicolumn{4}{|c|}{ Low SES $(n=141)$} & \multicolumn{4}{|c|}{ High SES $(n=131)$} \\
\hline & Daily & $\begin{array}{l}\text { 3-4 times } \\
\text { a week }\end{array}$ & $\begin{array}{l}\text { Once or twice } \\
\text { a week }\end{array}$ & $\begin{array}{l}\text { Occasionally } \\
\text { or nil }\end{array}$ & Daily & $\begin{array}{l}\text { 3-4 times } \\
\text { a week }\end{array}$ & $\begin{array}{l}\text { Once or twice } \\
\text { a week }\end{array}$ & $\begin{array}{l}\text { Occasionally } \\
\text { or nil }\end{array}$ \\
\hline \multicolumn{9}{|l|}{ Cereals and millet } \\
\hline Rice & 100 & 0 & 0 & 0 & 100 & 0 & 0 & 0 \\
\hline Wheat & 43.6 & 6.4 & 36.6 & 13.4 & 80.2 & 2.3 & 16.0 & 1.5 \\
\hline Jowar & 8.5 & 0 & 19.8 & 71.7 & 2.3 & 0 & 16.8 & 81.3 \\
\hline Ragi & 0 & 0 & 2.8 & 97.2 & 1.5 & 0 & 6.9 & 91.6 \\
\hline Pulses & 26.2 & 20.6 & 52.5 & 0.7 & 55.8 & 13.7 & 30.5 & 0 \\
\hline Roots and tubers & 90.1 & 4.3 & 5.6 & 0 & 90.1 & 1.5 & 7.6 & 0.8 \\
\hline $\begin{array}{l}\text { Flesh foods, including } \\
\text { poultry and eggs }\end{array}$ & 14.2 & 15.6 & 63.1 & 7.1 & 19.8 & 6.1 & 25.2 & 48.9 \\
\hline Nuts and oil seeds & 13.5 & 9.2 & 62.4 & 14.9 & 43.5 & 4.6 & 44.3 & 7.6 \\
\hline Other vegetables & 14.2 & 15.6 & 63.1 & 7.1 & 91.6 & 1.7 & 6.7 & 0 \\
\hline Carbonated drinks & 0.7 & 3.5 & 50.4 & 45.4 & 3.1 & 9.2 & 50.4 & 37.3 \\
\hline Instant foods & 0.7 & 2.1 & 50.4 & 46.8 & 28.2 & 3.1 & 37.4 & 31.3 \\
\hline
\end{tabular}

to the intake of milk and milk products, $96 \%$ of the children belonging to the high-SES group consumed these products daily, whereas among low-SES students, only $70 \%$ of them consumed milk and milk products daily.

\section{Snacks and carbonated drinks}

About $50 \%$ of children in both income groups consumed carbonated drinks at least once or twice a week (Table 1); there was no significant difference in the intake of carbonated drinks between the SES groups. For fast foods like corn flakes and noodles, $28 \%$ of children from the high-income group consumed these foods daily, whereas $50 \%$ of children from the lowincome group consumed these foods once or twice a week (Table 1).

\section{Impact of nutrition education}

The children's nutrition knowledge was assessed by a questionnaire containing various questions related to food and nutrition. The percentages of children who answered each question correctly at baseline and also after intervention are given in Table 2. It was observed that children from the high-SES group performed better

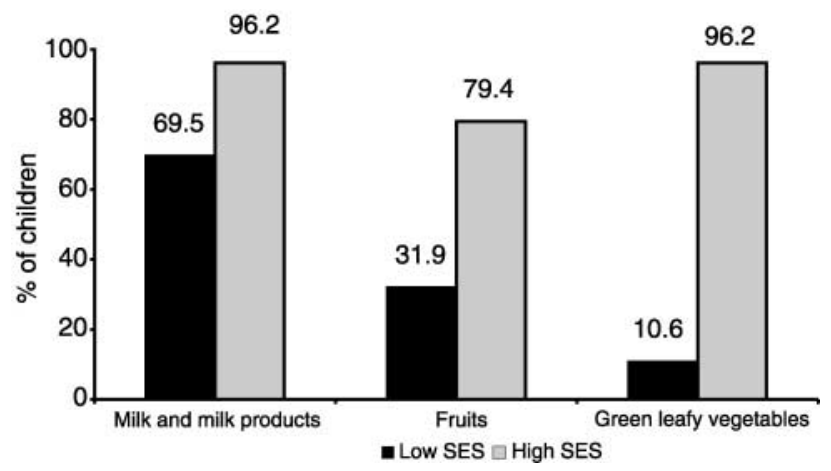

Fig. 1 Daily intakes of milk and milk products, fruits and green leafy vegetables among schoolchildren attending selected schools in Hyderabad, by socio-economic status (SES) (i.e. answered more questions correctly) than those from the low-SES group. After the intervention, an improvement in knowledge level with respect to each of the specific questions was observed, irrespective of SES. However, question numbers 6, 10, 12 and 17 showed a significant $(P<0.01)$ improvement in the percentage of correct answers among children of the high-SES group (Table 2). This indicates the need for repeated interventions among children with low SES.

The percentage score was computed for each child by summing up the scores for all of the questions in the knowledge assessment. The baseline data indicated that the high-SES children scored better (58\%) than the lowSES children (39\%) (Table 3). However, as also shown by the baseline data, before intervention there was no difference in nutrition knowledge levels between the experimental and control groups of both low- and highSES groups. Intervention by slides, posters and folders significantly improved the nutrition knowledge levels of children in both income groups, with the average scores at baseline and after intervention being significantly different in children from the experimental group irrespective of SES (Table 3).

\section{Breakfast and snack preferences}

As regards the breakfast preferences (traditional/fast food) of the schoolchildren, the intake of traditional food was similar in both high- and low-income groups (Table 4). The majority of children preferred traditional breakfast preparations like $i d l y$ and dosa (a fermented preparation made from rice and legumes). A small percentage of the children (22\%) from the high-SES group preferred fast food items to traditional food items for breakfast. Among snacks, $16 \%$ of the low-income and $22 \%$ of the highincome schoolchildren preferred baked preparations. The preference for fast food items was significantly greater $(P<0.001)$ among children from the high-income group (Table 4). 
Table 2 Percentage of schoolchildren $(n=272)$, attending selected schools in Hyderabad, who answered the knowledge assessment questionnaire correctly, by socio-economic status (SES)

\begin{tabular}{|c|c|c|c|c|c|}
\hline \multirow[b]{3}{*}{ Question } & & \multicolumn{4}{|c|}{ Experimental group } \\
\hline & & \multicolumn{2}{|c|}{ Low SES } & \multicolumn{2}{|c|}{ High SES } \\
\hline & & Baseline & After intervention & Baseline & After intervention \\
\hline 1 & CARBO & 79.1 & 82.2 & 92.5 & 86 \\
\hline 2 & EXCESS & 37.3 & 44.4 & 67.2 & 60.5 \\
\hline 3 & VITA-MICRO & 58.2 & 86.7 & 82.1 & 88.4 \\
\hline 4 & $\mathrm{CAL}-\mathrm{RICH}$ & 79.1 & 82.2 & 68.7 & 90.7 \\
\hline 5 & FERMENTED & 62.7 & 64.4 & 46.3 & 51.2 \\
\hline 6 & BODY-BUILD & 13.4 & 26.7 & 31.3 & 39.5 \\
\hline 7 & FRUITS & 7.5 & 28.9 & 49.3 & 60.5 \\
\hline 8 & VEG & 7.5 & 31.1 & 37.3 & 76.7 \\
\hline 9 & STAPLE-FOOD & 1.5 & 17.8 & 26.9 & 55.8 \\
\hline 10 & LO-HIMO & 3 & 35.6 & 13.4 & 44.2 \\
\hline 11 & VIT-A & 19.4 & 35.6 & 56.7 & 93 \\
\hline 12 & PRO-RICH & 11.9 & 35.6 & 56.7 & 74.4 \\
\hline 13 & VIT-B & 14.9 & 26.7 & 34.3 & 44.2 \\
\hline 14 & VIT-C & 6 & 17.8 & 31.3 & 30.2 \\
\hline 15 & ENG-RICH & 6 & 17.8 & 13.4 & 30.2 \\
\hline 16 & COOKEDFOOD & 80.6 & 88.9 & 95.5 & 97.7 \\
\hline 17 & STREET FOOD & 43.3 & 66.7 & 88.1 & 93 \\
\hline 18 & YELL\&ORG & 80.6 & 91.1 & 79.1 & 90.7 \\
\hline 19 & MILK\&SOYA & 61.2 & 82.2 & 68.7 & 65.1 \\
\hline 20 & ENG FREIT & 67.2 & 82.2 & 89.6 & 97.7 \\
\hline 21 & SPROUTED & 71.6 & 77.8 & 88.1 & 97.7 \\
\hline 22 & FOOD STORE & 53.7 & 71.1 & 80.6 & 88.4 \\
\hline 23 & NUT VALUE & 32.8 & 57.8 & 83.6 & 81.4 \\
\hline 24 & PRACTICE & 86.6 & 93.3 & 85.1 & 97.7 \\
\hline 25 & IODINE & 22.4 & 48.9 & 38.8 & 87.4 \\
\hline 26 & DEF-A & 31.3 & 48.9 & 61.2 & 95.3 \\
\hline 27 & HEL-BODY & 9 & 31.1 & 58.2 & 74.4 \\
\hline
\end{tabular}

\section{Discussion}

This study was part of a baseline survey of the nutrition knowledge levels of schoolchildren before planning a nutrition intervention programme for them. It was the first time an FFQ had been administered to this particular age group in India and the response was encouraging. There are a number of studies in the literature from Western countries, mostly epidemiological, in which FFQs have been administered to children ${ }^{5}$. The FFQ allows an assessment of the dietary intake of a large number of

Table 3 Nutrition knowledge level of schoolchildren attending selected schools in Hyderabad, by socio-economic status (SES)

\begin{tabular}{lccc}
\hline & \multicolumn{3}{c}{ Score $(\%)$, mean \pm standard deviation } \\
\cline { 2 - 4 } Group & Baseline & $\begin{array}{c}\text { After } \\
\text { intervention }\end{array}$ & $\begin{array}{c}\text { Knowledge } \\
\text { increment }\end{array}$ \\
\hline Low SES & & & \\
Experimental & $39.0 \pm 10.2$ & $48.4 \pm 13.9$ & $9.04 \pm 13.51$ \\
Control & $40.0 \pm 8.7$ & $42.5 \pm 8.2$ & $1.71 \pm 5.6$ \\
$P$-value & $\mathrm{NS}$ & 0.01 & 0.001 \\
High SES & & & \\
Experimental & $58.1 \pm 12.9$ & $71.0 \pm 11.6$ & $12.31 \pm 11.91$ \\
Control & $56.0 \pm 13.8$ & $62.1 \pm 11.2$ & $5.91 \pm 12.27$ \\
$P$-value & $\mathrm{NS}$ & $0.001^{*}$ & $<0.01$ \\
\hline
\end{tabular}

NS - not significant.

*indicates significant $(P<0.001)$. children, thus improving the power of the study, and it is relatively inexpensive to administer. The survey of food preferences and nutrition-related knowledge elicited a good response from the participants. A study from the National Institute of Nutrition on students attending an engineering college also showed that their diets were qualitatively adequate ${ }^{6}$. Children do not always choose what they eat; their parents decide and prepare the food for them. Hence, there is a need to reach out to their parents and especially their mothers, who are directly involved in the preparation of meals for the family.

All of the children in the study sample consumed rice at least twice daily. It may be noted that cereals are the major staple food of the population in India and Andhra Pradesh is the major rice-cultivating state. In the present study all children, irrespective of income level, consumed GLV at least once a week. According to WHO, consumption of GLV more than three times per week is considered necessary for the effective prevention of vitamin A deficiency in children. The children in the higher SES group consumed GLV almost daily, which is a very encouraging practice (Fig. 1).

Bailey et al. reported low intakes of fresh fruits and vegetables among adolescents of low-income households ${ }^{7}$. Thimmayamma et al. reported higher intakes of milk and fruits in a sample of higher-income groups in Hyderabad $^{8}$. Woodward also reported similar findings in a 
Table 4 Breakfast/snack preferences of schoolchildren attending selected schools in Hyderabad, by socio-economic status (SES)

\begin{tabular}{lccc}
\hline & \multicolumn{3}{c}{ Percentage of children } \\
\cline { 2 - 4 } & Low SES $(n=141)$ & High SES $(n=131)$ & Chi-square value \\
\hline Breakfast preference & & & \\
$\quad$ Traditional & 68.8 & 64.1 & $30.69(P<0.001)$ \\
$\quad$ Fast food & 2.1 & 22.2 & \\
$\quad$ Both traditional and fast food & 29.1 & 13.7 & $12.40(P<0.05)$ \\
Snack preference & & & \\
$\quad$ Baked items & 16.3 & 22.1 & \\
Fried items & 5.0 & 6.9 & \\
Fruits & 7.1 & 18.3 & \\
$\quad$ Beverages & 14.2 & 9.9 & \\
$\quad$ Others & 57.4 & 42.7 & \\
\hline
\end{tabular}

survey involving adolescents 9 . A number of studies in the literature on adolescent diets, mostly from Western countries, have focused on the habit of snacking or eating between meals ${ }^{10}$. Some studies found that the foods most often associated with snacking are largely of the emptycalorie type, e.g. carbonated beverages; and by replacing the more nutrient-dense beverages, and milk in particular, these drinks may depress overall intakes of calcium, magnesium, riboflavin, vitamin A and vitamin C. In a survey on consumer attitudes towards processed foods conducted in Delhi, Shaw et al. reported that a maximum number of adolescents (94\%) consume carbonated drinks $^{11}$

The present study has dealt with the qualitative aspects of the dietary intake pattern of Indian schoolchildren. It does not provide quantitative data on diet and nutrition. However, the information gathered here along with the children's nutrition-related knowledge will serve as baseline data for preparing a nutrition education package. For example, the children can be encouraged to consume more natural fruit juices instead of carbonated beverages. Carbonated drinks contain phosphoric acid, may damage tooth enamel and can affect appetite, if taken in excessive amounts ${ }^{12}$. Similarly, there are certain dietary behaviours among these children that need to be encouraged, i.e. daily intake of milk and fruits, etc., whereas frequent consumption of fried foods, fast foods and carbonated drinks needs to be discouraged. These points can be incorporated into the nutrition education package, which will be targeted at this group.

\section{Acknowledgements}

We thank Drs Kamala Krishnaswamy (former Director), B Sivakumar (Officer-In-Charge) and TC Raghuram (Deputy Director \& Head) of the Extension and Training Division, National Institute of Nutrition, Hyderabad for their encouragement in conducting the study. Thanks are due to the principals of Harvard Public School, Vasavi Public School, Govt. Railway Girls High School and Govt. High School, Moulali, for their co-operation and valuable help in completing this project work. We thank Drs K Vijaraghavan and D Hanumantha Rao for their most helpful comments on the manuscript.

Contributors: T.V. (Principal Investigator) participated in developing the study protocol and secured the funding; K.K.M. (Co-Investigator (Guarantor)) assisted in developing the FFQ and helped in preparation of the manuscript; D.R.R. (Co-Investigator) contributed to data collection and interpretation, and also helped in drafting and revising the manuscript; G.M.A. (Co-Investigator) assisted in designing study and performed the statistical analysis.

Conflict of interest: none stated.

\section{References}

1 Pietinen P, Hartman AM, Happa G, Rasanen L, Haapakoski J, Palmgren $\mathrm{J}$, et al. Reproducibility and validity of dietary assessment instruments. A self-administered food use questionnaire with a portion size picture \& booklet. American Journal of Epidemiology 1988; 128: 655-66.

2 Clancy-Hepburn K, Hickey AA, Nevill G. Children's behaviour responses to TV food advertisements. Journal of Nutrition Education 1974; 6: 93.

3 Chu YS, Kolonel NL, Hankin JH, Lee J. A comparison of frequency and quantitative dietary methods for epidemiological studies of diet and disease. American Journal of Epidemiology 1984; 119(3): 323-34.

4 National Institute of Nutrition. Nutrition Profile of a Community in Haryana - Sonipat District. Hyderabad: Indian Council of Medical Research, 1996; 5.

5 Samet MJ, Humble GC, Skipper EB. Alternatives in the collection and analysis of food frequency interview data. American Journal of Epidemiology 1984; 120(4): 572-81.

6 National Institute of Nutrition. Annual Report: Diet, Nutritional Status and Food Beliefs of Adolescent Girls, 1994-95. Hyderabad: Indian Council of Medical Research, 1995; 101-2.

7 Bailey DA, McKay HA, Mirwald RL, Crocker PR, Faulkner RA. A six year longitudinal study of the relationship of physical activity to bone mineral accrual in growing children: The University of Saskatchewan Bone Mineral Accrual Study. Journal of Bone and Mineral Research 1999; 14: 1672-9.

8 Thimmayamma BVS, Satyanarayana K, Rao K, Parvathi Rao, Swaminathan MC. The effect of socio-economic differences 
on the dietary intake of urban population in Hyderabad Indian Journal of Nutrition and Dietetics 1973; 10: 8 .

9 Woodward DR. What influences adolescent food intake. Human Nutrition. Applied Nutrition 1986; 40A: 185-94.

10 Lien N, Lytle LA, Klepp KI. Stability in consumption of fruit vegetables and sugary foods in a cohort from age 14 to 21 Preventive Medicine 2001; 33(3): 217-26.
11 Shaw A, Mathur P, Mehrotra. A study of consumer attitude towards processed foods. Journal of Indian Food Packers 1993; XI(VII): 2.

12 National Institute of Nutrition. Dietary Guidelines for Indians. Hyderabad: Indian Council of Medical Research, 1998; 56. 